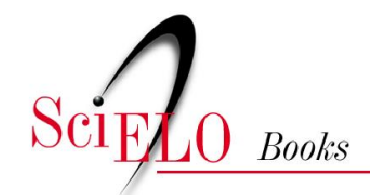

\title{
A verdadeira utopia
}

\author{
Slavoj Zizek
}

\section{SciELO Books / SciELO Livros / SciELO Libros}

ZIZEK, S. A verdadeira utopia. In: SOUSA, C. M., org. Um convite à utopia [online]. Campina Grande: EDUEPB, 2016. Um convite à utopia collection, vol. 1, pp. 291-301. ISBN: 978-85-7879488-0. Available from: doi: 10.7476/9788578794880.0008. Also available in ePUB from: http://books.scielo.org/id/kcdz2/epub/sousa-9788578794880.epub.

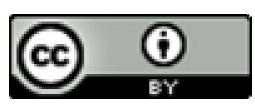

All the contents of this work, except where otherwise noted, is licensed under a Creative Commons Attribution 4.0 International license.

Todo o conteúdo deste trabalho, exceto quando houver ressalva, é publicado sob a licença Creative Commons Atribição 4.0.

Todo el contenido de esta obra, excepto donde se indique lo contrario, está bajo licencia de la licencia Creative Commons Reconocimento 4.0. 


\section{A VERDADEIRA UTOPIA ${ }^{1}$}

Slavoj Zizek ${ }^{2}$

Para instaurar uma forma diferente de funcionamento do poder, que vá além dos limites da democracia representativa, permanecer fiel à ideia comunista não é suficiente. Devem ser localizados, na realidade histórica, os antagonismos que fazem dessa ideia uma urgência prática. Deve-se, em primeiro lugar, transformar de maneira crítica os aparatos conceituas de Marx. Por causa de sua negligência quanto à dimensão social do a general intellect $^{3}$, Marx não vislumbrou a possibilidade de privatização do

1 Texto traduzido por Maria Beatriz de Medina para a Revista Filosofia Conhecimento Prático, Edição 51, e disponibilizado no site da própria publicação: http://filosofia.uol.com.br/filosofia/ideologia-sabedoria/31/artigo 28143-1.asp

2 Slavoj Žižek (1949) é um filósofo esloveno cujas influências principais são os pensamentos de Karl Marx, Jacques Lacan e Hegel. Atua nos campos da teoria política, análise cultural e cinematográfica e teoria psicanalítica. É professor da Universidade de Liubliana e professor convidado da Universidade de Vermont (EUA).

3 O termo general intellect significa, em linhas gerais, a inteligência social ou coletiva, o trabalho imaterial. De certa forma, se opõe ao conceito de propriedade intelectual individualizada. 
próprio general intellect - é isto que está no coração da batalha pela "propriedade intelectual".

Nisso Antonio Negri está certo: sob esse ponto de vista, a exploração no sentido marxista clássico não é mais possível - e é por isso que ela tem de ser reforçada, cada vez mais, por medidas legais diretas, ou seja, por uma força não econômica. É por isso que hoje a exploração assume cada vez mais a forma de uma renda. Como afirma Carlo Vercellone, o capitalismo pós-industrial é caracterizado pelo "tornar-se renda do lucro". E é por isso que a autoridade direta é necessária. É preciso impor as condições legais (arbitrárias) para que se extraia a renda, condições que não são mais "espontaneamente" geradas pelo mercado.

Talvez aqui resida a "contradição" fundamental do capitalismo "pós-moderno" contemporâneo. Enquanto sua lógica é desreguladora, "antiestatal”, nomática/desterritorializante etc., a tendência principal do "tornar-se-renda-do-lucro" assinala um fortalecimento do papel do Estado, cuja função (não somente) reguladora é mais e mais onipresente. Desterritorialização dinâmica coexiste com e se apoia mais e mais em intervenções autoritárias do Estado e seus aparelhos legais (e outros). O que é possível discernir no horizonte do nosso porvir histórico é, assim, uma sociedade em que liberalismo pessoal e hedonismo coexistem com (e são sustentados por) uma complexa rede de mecanismos estatais regulatórios. Longe de desaparecer, o Estado está se fortalecendo.

Em outras palavras, quando, devido ao papel crucial do general intellect (conhecimento e cooperação social) na criação da riqueza, formas de riqueza estão mais e mais "fora de quaisquer proporções com o tempo de trabalho direto envolvido em sua produção", o resultado não é, como Marx parece esperar, a autodissolução do capitalismo, mas a transformação gradual e relativa do lucro gerado pela exploração da força de trabalho em renda apropriada pela 
privatização do general intellect. Tomemos o caso de Bill Gates. Como ele se tornou o homem mais rico do mundo? Sua riqueza não tem nada a ver com os custos de produção dos produtos vendidos pela a Microsoft (pode-se até mesmo argumentar que a Microsoft está pagando a seus trabalhadores intellectuais um salário relativamente alto), isto é, a riqueza de Gates não é resultado de seu sucesso em produzir bons softwares por preços mais baixos do que seus competidores, ou com uma maior "exploração" dos trabalhadores intelectuais con tratados. Fosse esse o caso, a Microsoft já teria ido à falência há muito tempo. As pessoas teriam aderido em massa a programas alternativos e gratuitos, como o a Linux - que, de acordo com especialistas, possui melhor desempenho do que os programas da Microsoft .

Por que, então, milhões de pessoas ainda compram produtos da Microsoft ? Porque a Microsoft se impõe como um padrão quase universal, (quase) monopolizando o mercado, uma espécie de encarnação do general intellect. Gates se tornou o homem mais rico do mundo em algumas décadas apropriando-se da renda cobrada pela permissão, dada a milhões de trabalhadores intelectuais, de participar da forma de general intellect que ele privatizou e controla. É verdade, então, que os trabalhadores intelectuais de hoje não estão mais separados das condições objetivas de seu trabalho (eles possuem seu próprio PC etc.), o que seria, em Marx, a descrição da "alienação" capitalista? Sim, mas, mais fundamentalmente, não. Eles foram mutilados do campo social de seu próprio trabalho, do general intellect - que por sua vez é mediado pelo capital privado.

E o mesmo acontece com os recursos naturais. Sua exploração é uma das maiores fontes de renda hoje em dia, acompanhada pela luta por quem irá controlar essa renda, as populações do Terceiro Mundo ou as corporações ocidentais. A ironia suprema é que, para 
explicar a diferença entre força de trabalho - que, em seu uso, produz mais-valia sobre seu próprio valor - e outras mercadorias - cujo valor é simplesmente consumido em seu uso, sem envolver exploração -, Marx menciona como exemplo de mercadoria "comum" o petróleo, a mesma mercadoria que hoje é a fonte de extraordinários "lucros". Aqui também não faria sentido vincular os aumentos e as quedas do preço do petróleo à exploração do trabalho - o custo de produção é negligenciável, o preço que pagamos pelo petróleo é a renda que pagamos aos proprietários desses recursos por sua escassez e oferta limitada.

\section{Antagonismo e Protagonismo Global}

A única questão verdadeira hoje é: o capitalismo global contém antagonismos fortes o suficiente para impedir sua reprodução indefinida? Existem, penso eu, quatro desses antagonismos: a ameaça iminente de uma catástrofe ecológica, o caráter inapropriado da propriedade privada para designar a chamada "propriedade intelectual”, as implicações socioéticas dos novos desenvolvimentos tecnocientíficos (especialmente na biogenética) e, por último, mas não menos importante, as novas formas de apartheid, os novos muros e as favelas. Há uma diferença qualitativa entre este último aspecto, a lacuna que separa os excluídos dos incluídos, e os outros três, que designam os domínios daquilo que Hardt e Negri chamaram de "comuns", a substância partilhada do ser social cuja privatização é um ato violento a que se deve resistir, igualmente, com meios violentos, se necessário:

- os comuns da cultura, as formas imediatamente socializadas de capital "cognitivo", primariamente a linguagem, nosso meio de comunicação e educação, mas também a infraestrutura comum do transporte público, da eletricidade, dos correios etc. (se o monopólio fosse permitido 
a Bill Gates, chegaríamos à situação absurda em que um único indivíduo seria literalmente dono da tessitura, do software de nossa rede básica de comunicação);

- os comuns da natureza externa ameaçados pela poluição e exploração (do petróleo às florestas e habitats naturais);

- os comuns da natureza interna (a herança biogenética da humanidade): com a nova tecnologia biogenética, a criação do novo homem, no sentido literal de mudar a natureza humana, se torna uma perspectiva realista.

O que todas essas lutas têm em comum é a preocupação com os potenciais destrutivos, inclusive a autoaniquilação da própria humanidade, se fosse dada carta branca à lógica capitalista de enclausuramento desses comuns. Nicholas Stern estava correto em caracterizar a crise ambiental como "o maior fracasso do mercado na história da humanidade” (Revista Time, 24/12/2007). Então, quando Kishan Khoday, um líder de equipe da ONU, escreveu recentemente que "existe um espírito crescente de cidadania ambiental global, um desejo de fazer da mudança do clima uma questão de preocupação comum de toda a humanidade", devese dar toda ênfase nos termos "cidadania global" e "preocupação comum" - a necessidade de estabelecer uma organização e um engajamento plítico globais que, neutralizando e canalizando os mecanismos de mercado, representem uma perspectiva propriamente comunista.

É essa referência aos "comuns" que justifica ressuscitar a palavra comunismo. Ela nos permite ver o "enclausuramento" em marcha dos comuns como um processo de proletarização daqueles que estão, assim, excluídos de sua própria substância. A situação histórica de hoje não só não nos compele a abandonar a noção de proletariado, da posição do proletariado; ao contrário, ela nos compele a radicalizá-la a um nível existencial para além da imaginação 
de Marx. Necessitamos de uma noção mais radical do sujeito proletário, um sujeito reduzido a um ponto evanescente do cogito cartesiano, privado de seu conteúdo substancial.

Por esa razão, a nova política emancipatória não será mais o ato de um agente social particular, mas uma explosiva combinação de diferentes agentes. O que nos une é que, em contraste com a clássica imagem dos proletários que não tem "nada a perder senão seus grilhões", corremos o perigo de perder tudo. A ameaça é que sejamos reduzidos a um sujeito cartesiano abstratamente vazio, desprovido de todos os conteúdos substanciais, desapropriado de substância simbólica e com a base genética manipulada, condenado a vegetar num meio ambiente inabitável. Essa tripla ameaça a totalidade de nosso ser nos torna, de certo modo, todos proletários, reduzidos à "subjetividade sem substância", como Marx afirma nos Grundrisse. O desa o ético-político é reconhecermos a nós mesmos nessa figura - de certa forma, todos nós somos excluídos, tanto da natureza como de nossa própria substância simbólica. Hoje somos todos potencialmente Homo sacer, e a única forma de evitar que nos tornemos um é atuando preventivamente.

Comunismo é hoje não o nome da solução, mas o nome do problema, o problema dos comuns em todas as dimensões - os comuns da natureza como a substância de nossa vida, o problema de nossa biogenética comum, o problema de nossa cultura comum ("propriedade intelectual") e, por último, mas não menos importante, diretamente o problema dos comuns como espaço universal da humanidade, do qual ninguém deveria ser excluído. Isso porque, como colocou Linera, nosso horizonte tem de permanecer comunista - horizonte não como um ideal inacessível, mas um espaço mental no qual nos movemos. Isso é impossível? Nossa resposta deveria ser o paradoxo que retorna ao ponto que começamos: a Soyons realistes, demandons L'impossible. A verdadeira utopia hoje é a de que seremos capazes de resolver nossos problemas com 
transformações modestas no sistema existente. A única opção realista é fazer o que parece impossível nesse sistema.

Lembremos da definição surpreendentemente relevante de Paulo sobre uma luta emancipatória: "Porque não temos que lutar contra a carne e o sangue, mas contra os principados, contra as potestades, contra os príncipes /kosmokratoras/ das trevas deste século, contra as hostes espirituais da maldade, nos lugares celestiais". Ou, traduzindo em nossa linguagem de hoje: "nossa luta não é contra indivíduos corruptos concretos, mas contra todos aqueles no poder em geral, contra sua autoridade, contra a ordem global e a mistificação ideológica que a sustenta”. Se engajar nessa luta signi ca endossar a fórmula de Badiou, mieux vaut un desastre qu'un desètre, melhor assumir o risco e se engajar na fidelidade ao evento-verdade, mesmo que essa fidelidade termine numa catástrofe, do que vegetar na sobrevivência hedonista-utilitarista sem-eventos daquilo que Nietzsche chamou de último homem. O que devemos rejeitar é a ideologia liberal-vitimista que reduz a política a evitar o pior, a renunciar de todos os projetos positivos e perseguir a opção menos ruim - ou, como notou amargamente Arthur Feldmann, o escritor judeu vienense, o preço que usualmente pagamos para sobreviver é a própria vida.

\section{Crença na utopia é ainda a melhor forma de questionar a exclusão social $^{4}$}

Eleger a internet como exemplo democrático é esconder diferenças sociais, institucionais e psicológicas entre as vidas "real" e "virtual".

4 Tradução de Luiz Roberto Mendes Gonçalves. Retirado de: http://cesarkiraly. opsblog.org/2008/06/03/crenca-na-utopia-slavoj-zizek/ 
Um dos grafites mais conhecidos dos muros de Paris em 1968 era: “As estruturas não andam pelas ruas!". Isto é, não se podem explicar as grandes manifestações de estudantes e trabalhadores do Maio de 68 como determinadas pelas mudanças estruturais na sociedade.

Mas, segundo [o psicanalista] Jacques Lacan, foi exatamente isso o que aconteceu em 1968: as estruturas saíram às ruas. Os eventos explosivos visíveis foram, em última instância, o resultado de um desequilíbrio estrutural - a passagem de uma forma de dominação para outra; nos termos de Lacan, do discurso do mestre para o discurso da universidade. Os protestos anticapitalistas dos anos 60 suplementaram a crítica padrão da exploração socioeconômica pelos temas da crítica social: a alienação da vida cotidiana, a "mercadorização" do consumo, a inautenticidade de uma sociedade de massa em que "usamos máscaras" e sofremos opressão sexual e outras etc.

\section{Prazer extremo}

Mas o novo espírito do capitalismo recuperou triunfalmente a retórica anti-hierárquica de 1968, apresentando-se como bem-sucedida revolta libertária contra as organizações sociais opressivas do capitalismo corporativo e do socialismo "realmente existente". O que sobreviveu da libertação sexual dos anos 1960 foi o hedonismo tolerante, facilmente incorporado a nossa ideologia hegemônica: hoje o prazer sexual não apenas é permitido, é ordenado - os indivíduos se sentem culpados quando não podem desfrutá-lo. A tendência às formas radicais de prazer (por meio de experiências sexuais e drogas ou outros meios de indução ao transe) surge em um momento político preciso: quando o "espírito de 68" esgota seus potenciais políticos. Nesse ponto crítico (meados dos anos 70), a única opção restante foi um direto e brutal empurrão para o real, que assumiu três formas principais: a busca por formas 
extremas de prazer sexual, a opção pelo real de uma experiência interior (misticismo oriental) e, finalmente, o terrorismo político de esquerda (Fração do Exército Vermelho na Alemanha, Brigadas Vermelhas na Itália etc.).

O que todas essas opções compartilham é um recuo do engajamento sociopolítico concreto para um contato direto com o real. Lembremos aqui o desafio de Lacan aos estudantes que protestavam: "Como revolucionários, vocês são histéricos que exigem um novo mestre. Vocês vão ganhar um”. E o ganhamos, sob o disfarce do mestre "permissivo" pós-moderno cuja dominação é mais forte por ser menos visível.

Sem dúvida, muitas mudanças positivas acompanharam essa passagem -basta citar as novas liberdades das mulheres e seu acesso a cargos de poder.Entretanto essa passagem para um outro "espírito do capitalismo" foi realmente tudo o que aconteceu nos eventos do Maio de 68, de modo que todo o entusiasmo ébrio de liberdade foi apenas um meio de substituir uma forma de dominação por outra? Muitos sinais indicam que as coisas não são tão simples. Se examinarmos nossa situação com os olhos de 1968, devemos lembrar o verdadeiro legado desse ano: seu núcleo foi uma rejeição ao sistema liberal-capitalista. É fácil zombar da idéia do "fim da história" de Francis Fukuyama, mas hoje a maioria é fukuyamista: o capitalismo liberal-democrático é aceito como a fórmula finalmente encontrada da melhor sociedade possível, e tudo o que se pode fazer é torná-la mais justa, tolerante etc.

\section{Ecologia e apartheid}

Hoje a única verdadeira questão é: nós endossamos essa naturalização do capitalismo ou o capitalismo global de hoje contém antagonismos fortes o suficiente para impedir sua infinita reprodução? Há (pelo menos) quatro desses antagonismos: a sombria 
ameaça da catástrofe ecológica, a inadequação da propriedade privada para a chamada "propriedade intelectual", as implicações socioéticas dos novos avanços tecnocientíficos (especialmente em biogenética) e as novas formas de apartheid, os novos muros e favelas. Os primeiros três antagonismos se referem aos domínios do que Michael Hardt e Toni Negri chamam de "comuns".

Há os "comuns de natureza externa" ameaçados pela poluição e a exploração (do petróleo a florestas e o próprio habitat natural), os "comuns de natureza interna" (o legado biogenético da humanidade) e os "comuns de cultura", as formas imediatamente socializadas de capital "cognitivo", basicamente a língua, nosso meio de educação e comunicação.

A referência a "comuns" justifica a ressurreição da idéia de comunismo: nos permite ver o envolvimento progressivo dos comuns como um processo de proletarização daqueles que são assim excluídos de sua própria substância. No entanto é apenas o antagonismo entre os "incluídos" e os "excluídos" que realmente justifica o termo comunismo. Em diferentes formas de favelas ao redor do mundo, presenciamos o rápido crescimento da população sem o controle do Estado, vivendo em condições meio fora-da-lei, em terrível carência de formas mínimas de auto-organização.

Se a principal tarefa da política emancipatória do século 19 foi romper o monopólio dos liberais burgueses por meio da politização da classe trabalhadora, e se a tarefa do século 20 foi despertar politicamente a imensa população rural da Ásia e da África, a principal tarefa do século 21 é politizar -organizar e disciplinar - as "massas desestruturadas" dos que vivem nas favelas.

Se ignorarmos esse problema dos excluídos, todos os outros antagonismos perdem seu viés subversivo. A ecologia se transforma em um problema de desenvolvimento sustentável, a propriedade intelectual em um complexo desafio jurídico, a biogenética em uma questão ética. 


\section{"Sejamos realistas"}

Sem o antagonismo entre incluídos e excluídos, poderemos nos encontrar em um mundo em que Bill Gates é o principal humanista, lutando contra a pobreza e as doenças, e Rupert Murdoch o maior ambientalista, mobilizando milhões de pessoas por meio de seu império da mídia. O verdadeiro legado de 1968 é melhor resumido na fórmula "soyons realistes, demandons l'impossible!” sejamos realistas, exijamos o impossível!].

A verdadeira utopia é a crença em que o sistema global existente pode se reproduzir indefinidamente. A única maneira de ser verdadeiramente realista é imaginar o que, dentro das coordenadas desse sistema, só pode parecer impossível. 